\title{
Glucagon responses to exercise-induced hypoglycaemia are improved by somatostatin receptor type 2 antagonism in a rat model of diabetes
}

\author{
Erwan Leclair $^{1} \cdot$ Richard T. Liggins $^{2}$ - Ashley J. Peckett ${ }^{1} \cdot$ Trevor Teich $^{1}$. \\ David H. Coy ${ }^{3}$ - Mladen Vranic ${ }^{4}$. Michael C. Riddell ${ }^{1}$
}

Received: 6 January 2016 / Accepted: 18 March 2016/Published online: 13 April 2016

(C) Springer-Verlag Berlin Heidelberg 2016

\begin{abstract}
Aims/hypothesis Regular exercise is at the cornerstone of care in type 1 diabetes. However, relative hyperinsulinaemia and a blunted glucagon response to exercise promote hypoglycaemia. Recently, a selective antagonist of somatostatin receptor 2, PRL-2903, was shown to improve glucagon counterregulation to hypoglycaemia in resting streptozotocin-induced diabetic rats. The aim of this study was to test the efficacy of PRL-2903 in enhancing glucagon counterregulation during repeated hyperinsulinaemic exercise.

Methods Diabetic rats performed daily exercise for 1 week and were then exposed to saline $(154 \mathrm{mmol} / \mathrm{l} \mathrm{NaCl})$ or PRL$2903,10 \mathrm{mg} / \mathrm{kg}$, before hyperinsulinaemic exercise on two separate occasions spaced 1 day apart. In the following week, animals crossed over to the alternate treatment for a third hyperinsulinaemic exercise protocol.

Results Liver glycogen content was lower in diabetic rats compared with control rats, despite daily insulin therapy
\end{abstract}

Electronic supplementary material The online version of this article (doi:10.1007/s00125-016-3953-0) contains peer-reviewed but unedited supplementary material, which is available to authorised users.

Michael C. Riddell

mriddell@yorku.ca

1 School of Kinesiology and Health Science, York University, Toronto, ON M3J 1P3, Canada

2 The Center for Drug Research and Development, Vancouver, BC, Canada

3 Department of Medicine, Peptide Research Labs, Tulane University Medical Center, New Orleans, LA, USA

4 Departments of Physiology and Medicine, University of Toronto, Toronto, ON, Canada $(p<0.05)$. Glucagon levels failed to increase during exercise with saline but increased three-to-six fold with PRL-2903 (all $p<0.05)$. Glucose concentrations tended to be higher during exercise and early recovery with PRL-2903 on both days of treatment; this difference did not achieve statistical significance $(p>0.05)$.

Conclusions/interpretation PRL-2903 improves glucagon counterregulation during exercise. However, liver glycogen stores or other factors limit the prevention of exercise-induced hypoglycaemia in rats with streptozotocin-induced diabetes.

Keywords Exercise · Glucagon · Hypoglycaemia · Somatostatin receptor antagonist - Type 1 diabetes

$\begin{array}{ll}\text { Abbreviations } \\ \text { BBDP } & \text { Diabetes-prone BioBreeding rat } \\ \text { CGM } & \text { Continuous glucose monitoring } \\ \text { SSTR } & \text { Somatostatin receptor } \\ \text { SSTR2a } & \text { Somatostatin receptor } 2 \text { antagonist } \\ \text { STZ } & \text { Streptozotocin }\end{array}$

Introduction

Non-severe and severe hypoglycaemia are frequent adverse effects of insulin therapy in diabetes mellitus [1, 2]. A fear of hypoglycaemia alters self-management of diabetes and prevents optimal glycaemic control [3]. The increased risk for hypoglycaemia in type 1 diabetes is related to an early defect in the glucagon response to developing hypoglycaemia [4] and subsequent impairments in the sympatho-adrenal and symptomatic responses to the same level of hypoglycaemia exposure over time [5].

Along with insulin therapy, regular exercise is at the cornerstone of patient health [5]. Unfortunately, exercise also 
increases hypoglycaemia risk in patients with diabetes [6-8]. The increased risk during and after exercise is likely multifactorial but primarily includes increased skeletal muscle insulin sensitivity $[9,10]$ a relative hyperinsulinaemia during the activity [11-13] and an attenuated glucagon response during exercise $[14,15]$. Even in well-controlled patients with type 1 diabetes who have not performed recent exercise, hyperinsulinaemia and a blunted glucagon response to moderate intensity aerobic exercise occur [14]. A vicious cycle of blunted counterregulatory responses to exercise and to hypoglycaemia develops if the two phenomena are held close together [16]. The mechanism for the blunted glucagon response to exercise (or to hypoglycaemia) in diabetes is unknown but could be related to autocrine or paracrine failures within the pancreatic islets themselves.

To date, a limited number of potential therapeutics have been tested in animal models that can improve counterregulation to hypoglycaemia, either by improving fuel sensing in the central nervous system [17] or by targeting the alpha cell directly [18]. Somatostatin is a peptide hormone released by the delta cells of the pancreas that suppresses the release of insulin and several counterregulatory hormones, including glucagon, catecholamines, growth hormone and cortisol [19]. In humans and in animal models, diabetes causes somatostatin levels to rise systemically $[20,21]$ and within the islets themselves [20, 22-24]. By antagonising somatostatin receptor (SSTR)2 with a selective SSTR2 antagonist (SSTR2a), PRL-2903, we have demonstrated that glucagon and corticosterone responses to insulin-induced hypoglycaemia are improved $[25,26]$, as is the depth and duration of hypoglycaemia [27]. It is currently unknown whether somatostatin antagonism can enhance glucagon secretion during exercise and help protect against exercise-induced hypoglycaemia in a setting of relative hyperinsulinaemia. The purpose of this study was to test the efficacy of an SSTR2a in restoring glucagon counterregulation and protection against hypoglycaemia during exercise in regularly active streptozotocin (STZ)-induced rat models of diabetes.

\section{Methods}

Experimental animals and ethics statement Male Sprague Dawley rats (125-150 g, Charles River, Québec, QC, Canada) were fed standard rodent chow (Ralston Purina, St Louis, MO, USA) and water ad libitum and were acclimatised to a $12 \mathrm{~h}$ light cycle for a period of 1 week before the induction of diabetes (week 0) using a single i.p. injection of STZ (65 mg/kg; Sigma, St Louis, MO, USA). This dose of STZ leaves some residual beta cell function in rats but the SSTR2a does not appear to markedly impact insulin section in this model $[26,27]$, probably because the beta cells in rats predominantly express SSTR5 rather than SSTR2 [25]. Two rats that did not become hyperglycaemic (blood glucose $<15 \mathrm{mmol} / \mathrm{l}$ ) following STZ administration were eliminated from the study. Rats were then placed on daily insulin therapy (split dose of insulin glargine (Sanofi, Laval, QC, Canada): $2.5 \mathrm{U} / \mathrm{kg}$ at 09:00 hours and at 16:00 hours; Humulin R insulin [Eli Lilly, Toronto, ON, Canada]: $5 \mathrm{U} / \mathrm{kg}$ at 16:00 hours) to simulate 'fair' glycaemic control during the experimental period. Four healthy rats, four rats with STZ-induced diabetes not receiving insulin and five diabetic rats receiving insulin treatment were used for liver glycogen assessment. The Guide for the care and use of laboratory animals, 8th edn (2011) was followed. All experiments were approved by the Animal Care Committee at York University (Toronto, ON, Canada) and were conducted in accordance with guidelines set by the Canadian Council for Animal Care.

Exercise habituation, SSTR2a treatment and acute exercise hypoglycaemia challenge Figure 1 shows the study design and timeline. Rats were first habituated to treadmill running over a 5 day period with a goal of establishing a running speed of $17 \mathrm{~m} / \mathrm{min}, 0 \%$ slope, for $30 \mathrm{~min}$ (week -1), corresponding to $\sim 80 \%$ of maximal oxygen consumption [28]. Following diabetes induction (week 0), daily treadmill running was resumed for an additional 5 days (week 1).

At 2 weeks after diabetes induction, three repeat exercise/ hypoglycaemic challenges were initiated over a 10 day period (with at least 1 day off between exposures). Chow, $15 \mathrm{~g}$, was provided to the animals at 18:00 hours the evening before, along with the usual dose of insulin glargine (Humulin $\mathrm{R}$ insulin was withheld). Twenty rats were randomly allocated into two groups and the experimenters were not blinded to the group assignment nor outcome assessments. One group of rats (Group 1, $n=10$ ) were treated with an SSTR2a (PRL-2903, $10 \mathrm{mg} / \mathrm{kg}$ i.p.) $90 \mathrm{~min}$ before exercise on the first two exercise/ hypoglycaemic challenges and then with saline $(154 \mathrm{mmol} / \mathrm{l}$ $\mathrm{NaCl}) 90$ min prior to the last exercise/hypoglycaemic challenge (Fig. 1). Conversely, a second group (Group 2, $n=10$ ) were treated with saline injection $(2 \mathrm{ml} / \mathrm{kg}) 90 \mathrm{~min}$ prior to exercise $(\mathrm{t}=-90 \mathrm{~min})$ on the first two exercise/hypoglycaemic challenges and then with the SSTR2a 90 min prior to the last exercise/hypoglycaemic challenge (Fig. 1). PRL-2903 administered i.p. reaches a peak plasma concentration $\left(C_{\max }\right)$ within $60 \mathrm{~min}$, with a half-life of $\sim 30 \mathrm{~h}$; with good target (pancreas) distribution sustained for at least $24 \mathrm{~h}$ (electronic supplementary material [ESM] Fig. 1).

This crossover design was selected because it allowed for the assessment of repeated SSTR2a exposure in a setting of recurrent exercise/hypoglycaemia with a prolonged drug washout period before a third exercise/hypoglycaemic exposure (Group 1). This design also allowed for the assessment of SSTR2a after recurrent exercise/hypoglycaemic challenge (Group 2). The SSTR2a (PRL-2903) was purchased by CPC Scientific (Sunnyvale, CA, USA) and the dose $(10 \mathrm{mg} / \mathrm{kg}$ 


\begin{tabular}{|c|c|c|c|c|c|}
\hline Week -1 & Week 0 & Week 1 & \multicolumn{2}{|c|}{ Week 2} & We \\
\hline \multirow[t]{3}{*}{$\begin{array}{c}\text { Treadmill } \\
\text { habituation }\end{array}$} & $\begin{array}{l}\text { Type } 1 \text { diabetes } \\
\text { induction }\end{array}$ & $\begin{array}{c}\text { Treadmill } \\
\text { rehabituation }\end{array}$ & $\begin{array}{c}\text { Challenge } \\
\text { day } 1\end{array}$ & $\begin{array}{c}\text { Challenge } \\
\text { day } 2\end{array}$ & $\begin{array}{c}\text { Challenge } \\
\text { day } 3\end{array}$ \\
\hline & & & SSTR2a & SSTR2a & Saline \\
\hline & & & Saline & Saline & SSTR2a \\
\hline
\end{tabular}

Fig. 1 Study design and timeline

body mass) approximated that given in our prior studies [25-27]. The antagonist was dissolved in saline and given in a $2 \mathrm{ml} / \mathrm{kg}$ volume.

To induce hyperinsulinaemia/hypoglycaemia during exercise, a subcutaneous bolus of Humulin R insulin (Eli Lilly, Toronto, ON, Canada) was administered $60 \mathrm{~min}$ before the start of exercise $(\mathrm{t}=-60 \mathrm{~min})$ using an in-house sliding scale, where $\mathrm{X}=$ baseline blood glucose concentration in $\mathrm{mmol} / \mathrm{l}$ and $\mathrm{Y}=$ target blood glucose concentration $(5.0 \mathrm{mmol} / \mathrm{l}$ in this study):

Bolus insulin dose $(\mathrm{U} / \mathrm{kg})=\left(\frac{\mathrm{X}-\mathrm{Y}}{\mathrm{X} \times 0.0749+1.8734}\right) \times \frac{2}{3}$

Pilot testing of this equation in our laboratory demonstrated that this target glucose concentration at rest $(5.0 \mathrm{mmol} / \mathrm{l})$ with a two-thirds correction promotes mild to moderate hypoglycaemia (whole-blood glucose $2-3 \mathrm{mmol} / \mathrm{l}$ ) by the end of $30 \mathrm{~min}$ exercise in a majority of STZ diabetic rats. This protocol is similar to one we have published previously in resting rats [27]. It has the advantage over the glucose clamp technique since it allows for the assessment of glucose recovery from hypoglycaemia.

Blood sampling for glucagon and glucose measurements Blood samples from a saphenous vein bleed $(\sim 175 \mu \mathrm{l})$ for basal glucagon were collected on a sedentary day at 1 week prior to the experimental procedures to limit blood volume depletion and handling stress. During the exercise/ hypoglycaemia challenges, saphenous blood was collected for plasma glucagon concentrations at the end of exercise $(\mathrm{t}=30 \mathrm{~min}$, where $\mathrm{t}=0$ is the start of exercise $)$ and at $40 \mathrm{~min}$ in recovery (i.e. $t=70 \mathrm{~min}$ ). Blood was collected in chilled tubes containing EDTA and Trasylol (Bayer Canada, Etobicoke, ON, Canada) and were assayed via radioimmunoassay (Rat Glucagon RIA kit, Millipore, Billerica, MA, USA) in duplicate. Blood glucose was measured throughout the experiment using a handheld glucometer (AlphaTRAK, Abbott Labs, Toronto, ON, Canada) with tail nick $(\mathrm{t}=-90,-60,-40$, $0,15,30,45,60,120$ and $150 \mathrm{~min})$. Hypoglycaemia was defined as a whole-blood glucose $\leq 3.9 \mathrm{mmol} / \mathrm{l}$. If blood glucose level was $\leq 1.5 \mathrm{mmol} / \mathrm{l}$, rats were monitored closely and treated with oral glucose gavage if deemed necessary.
Continuous blood glucose monitoring Continuous glucose monitoring (CGM) was performed in select animals using the iPro2 system (with Sof-sensor, Medtronic MiniMed, Northridge, CA, USA) to profile glucose control during a $42 \mathrm{~h}$ period. With these measurements, the effects of insulin treatment, feeding and the hypoglycaemic/exercise challenge could be monitored (see ESM Fig. 2 for an example CGM tracing). Rats were killed 6 days after their last exercise/ hypoglycaemic challenge via isoflurane overdose. Liver glycogen content was determined using a method modified from Carr and Neff [29].

Statistical analysis Two-way mixed ANOVA tests were used for time-dependent comparisons of glucagon and glucose concentrations for the two groups of rats (treatment group, time). Two-way repeated-measure ANOVAs (challenge day, time) were also used to compare glucose and glucagon levels between the first and second exercise/hypoglycaemic challenges for challenge days 1 and 2. Values are reported as means \pm SEM unless otherwise shown.

\section{Results}

Glucagon levels during exercise/hypoglycaemic challenges All rats were able to complete the $30 \mathrm{~min}$ of exercise. Figure 2 shows the glucagon levels for the SSTR2a-treated and salinetreated rats during the three exercise/hypoglycaemic challenges. Basal glucagon values were in accordance with other previously published data [25-27] and not significantly different between Groups 1 and 2 (Fig. 2). During all three challenges, glucagon concentrations increased significantly with SSTR2a by the end of exercise ( $\mathrm{t}=30 \mathrm{~min})$ but failed to increase with saline treatment. In Group 1, glucagon values at 30 min tended to be higher on day 2 compared with day 1 $(p=0.08)$. In Group 2, glucagon values were higher at $30 \mathrm{~min}$ on challenge day 3 , when they received SSTR2a, compared with animals given the saline treatment on that particular day $(p<0.05)$.

Glycaemic responses and change in glucagon levels Representative CGM tracings for an exercise/hypoglycaemic challenge day are shown in Fig. 3. Insulin administration and 


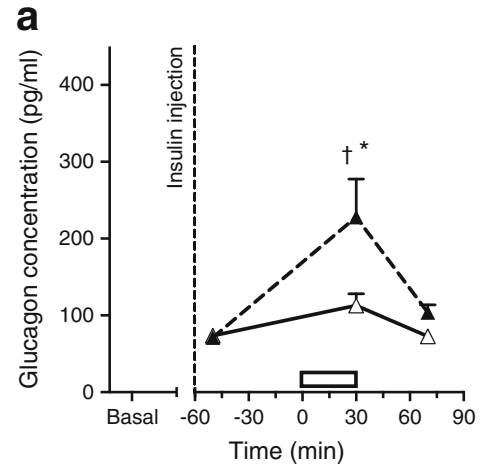

Fig. 2 Glucagon levels during the exercise/hypoglycaemic challenge on day 1 (a), day 2 (b) and day 3 (c). Dashed line, Group 1 (SSTR2a, SSTR2a, saline); solid line, Group 2 (saline, saline, SSTR2a). Black

exercise resulted in a rapid reduction in glucose levels, with hypoglycaemia observed at the end of exercise and in early recovery. While beneficial for profiling overall glycaemic management, considerable CGM error was noted when glucose levels were changing rapidly (Fig. 3), as has previously been documented [30-32].

Mean whole-blood glucose concentrations during the three exercise/hypoglycaemia challenges are shown in Fig. 4. The insulin dose at $\mathrm{t}=-60 \mathrm{~min}$ was similar between the two groups of animals on the three challenge days (Group 1: $3.2 \pm 0.6$ $\mathrm{U} / \mathrm{kg} ; 3.2 \pm 1.2 \mathrm{U} / \mathrm{kg} ; 2.9 \pm 1.3 \mathrm{U} / \mathrm{kg}$; Group 2: $2.8 \pm 1.3$ $\mathrm{U} / \mathrm{kg} ; 2.6 \pm 1.3 \mathrm{U} / \mathrm{kg} ; 3.0 \pm 1.0 \mathrm{U} / \mathrm{kg}$ on days $1-3$, respectively). Insulin administration lowered blood glucose to a nadir soon after the end of exercise. The number of rats requiring glucose gavage for severe hypoglycaemia was low $(n=4)$ but in all instances the requirement occurred after SSTR2a treatment. While glucose concentrations tended to be higher following SSTR2a treatment on exercise/hypoglycaemic challenge days 1 and 2, this difference did not achieve statistical significance, likely because of high glucose variability among the animals. Glucose concentrations tended to be lower in

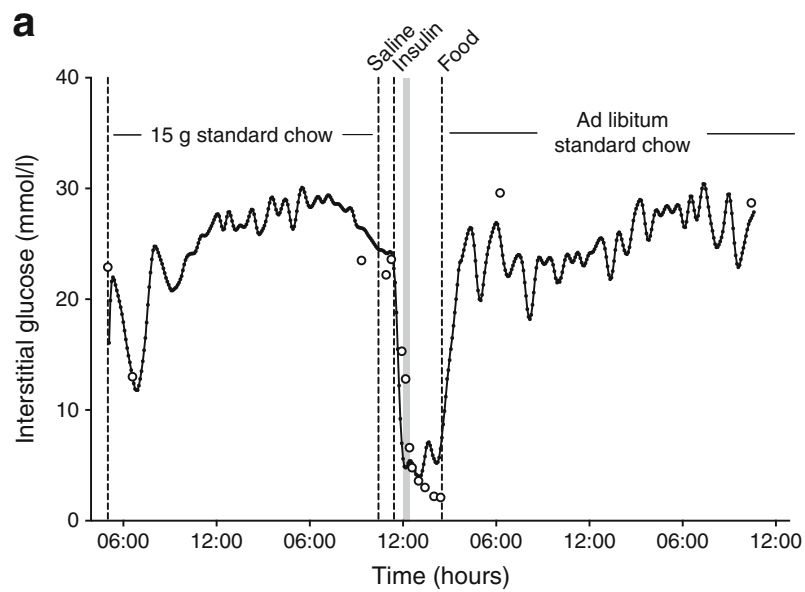

Fig. 3 Representative interstitial glucose tracing (by CGM) for an exercise/hypoglycaemic challenge day in (a) saline- and (b) SSTR2a-treated animals. White circles, whole-blood glucose values, as measured with a

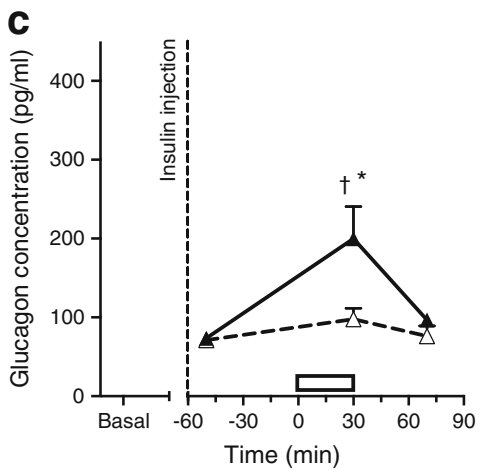

triangles, SSTR2a; white triangles, saline. ${ }^{\dagger}$ Significantly different from baseline, $p<0.05 ;{ }^{*}$ significantly different from saline, $p<0.05$. The rectangle represents the exercise period

SSTR2a-treated animals on challenge day 3 compared with the saline-treated group.

The change in glucagon level from baseline to 30 and 70 min after exercise is shown in Fig. 4 (insets). The increase in glucagon from baseline to 30 min was higher with SSTR2a compared with saline for all three challenges. The change from baseline to the $70 \mathrm{~min}$ time point was also higher in the SSTR2a-treated rats than in the saline-treated rats on challenge day $1(p<0.05)$, but not on the other days.

Figure 5 shows the fold change in glucagon levels from baseline to the 30 and $70 \mathrm{~min}$ time points vs the glucose concentrations measured at those same time points. A nonlinear one-phase decay model shows that, at the $30 \mathrm{~min}$ time point, a clear glucose threshold at about the hypoglycaemic threshold (blood glucose $3.9 \mathrm{mmol} / \mathrm{l}$ ) existed for the glucagon fold change in SSTR2a-treated rats, while no glycaemic threshold existed in saline-treated animals. At the 70 min time point, glucagon levels clustered around the basal levels even though the majority of rats were hypoglycaemic. No glycaemic threshold existed for glucagon response at $70 \mathrm{~min}$ in either treatment group. In a secondary analysis, rats that

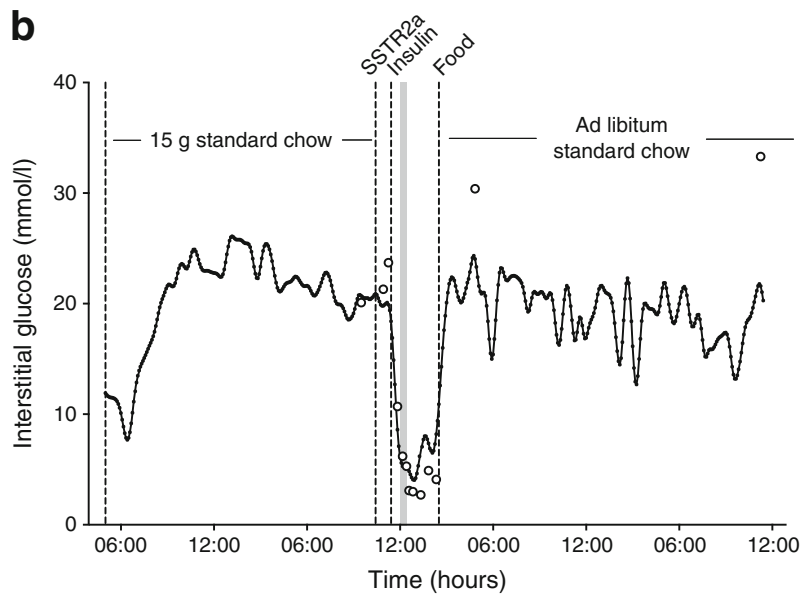

handheld glucometer; grey area, exercise. Note: CGM overestimates glucose levels during hypoglycaemia and tends to underestimate levels during hyperglycaemia 

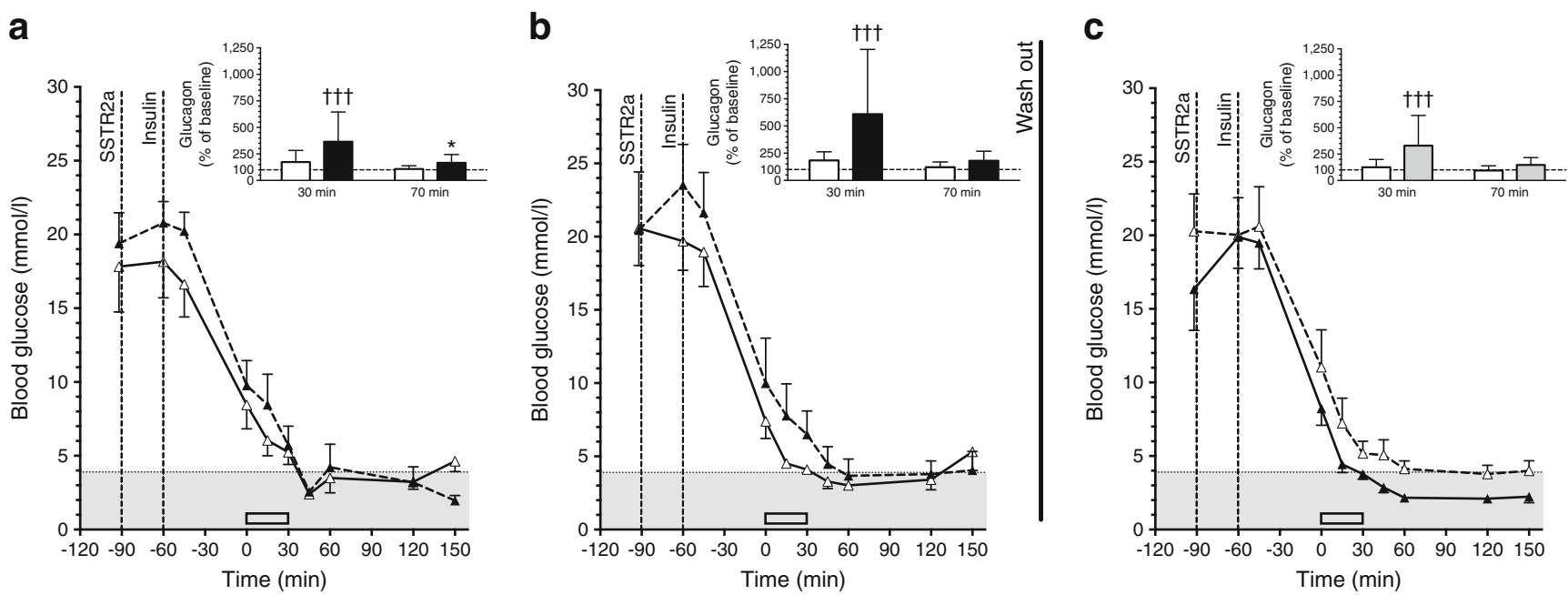

Fig. 4 Whole-blood glucose concentrations on day 1 (a), day 2 (b) and day 3 (c) and change in glucagon levels from baseline to 30 and $70 \mathrm{~min}$ after exercise during the three exercise/hypoglycaemia challenge days. Dashed and solid lines represent Groups 1 and 2, respectively. White triangles/bars, saline treatment. Black triangles/bars, SSTR2a treatment.

Grey bars, SSTR2a treatment on day 3 following saline treatment on days 1 and 2. Grey shading at the bottom of the graphs represents biochemical hypoglycaemia; the rectangle represents the exercise period. †ं Significantly different from saline at $30 \mathrm{~min}(p<0.001)$; ${ }^{*}$ significantly different from saline at $70 \mathrm{~min}(p<0.05)$

developed hypoglycaemia during the challenge (blood glucose $\leq 3.9 \mathrm{mmol} / \mathrm{l}$ ) but did not have a rise in glucagon concentration over baseline were deemed 'non-responders'. Rats were deemed 'responders' if hypoglycaemia occurred and peak glucagon levels increased by twofold compared with the baseline. Three 'responders' were identified of eight $(38 \%)$ in saline-treated groups at the $30 \mathrm{~min}$ time point vs nine of ten $(90 \%)$ in the SSTR2a-treated groups $\left(p<0.05, \chi^{2}\right.$ analysis).
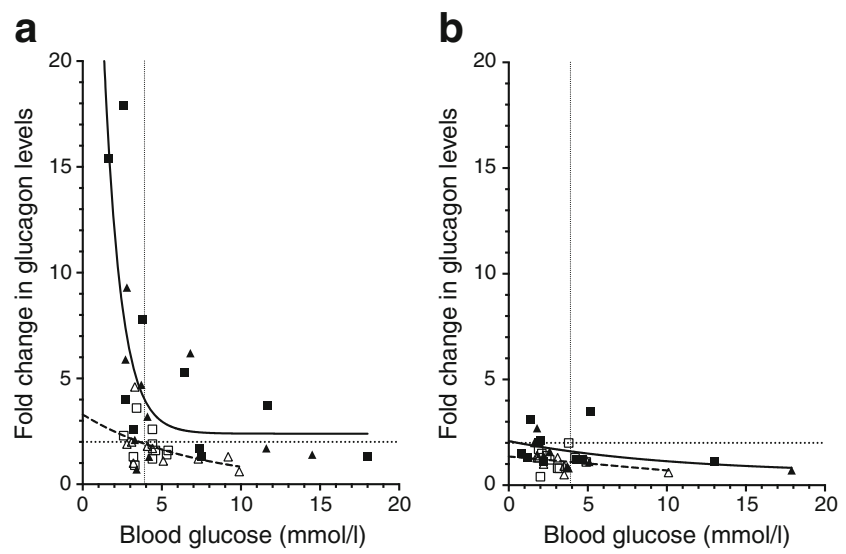

Fig. 5 Change in glucagon level from baseline at (a) 30 and (b) $70 \mathrm{~min}$ vs the corresponding glucose concentrations measured at those same time points during the first two hypoglycaemic/exercise challenge days. Dashed and solid lines show the best fit curves for data obtained after saline and SSTR2a treatment, respectively. White triangles/squares, day 1 and day 2 with saline treatment, respectively. Black triangles/squares, day 1 and day 2 with SSTR2a treatment, respectively. Vertical dotted line, hypoglycaemic threshold of $3.9 \mathrm{mmol} / \mathrm{l}$; horizontal dotted line, twofold increase in glucagon concentration. As shown, SSTR2a treatment increased glucagon levels in an exponential fashion when the hypoglycaemic threshold was achieved at the $30 \mathrm{~min}$ time point. This response was attenuated by the $70 \mathrm{~min}$ time point
The blood glucose nadir was not different between salineand SSTR2a-treated rats on day $1(3.0 \pm 0.54$ vs 3.0 $\pm 1.08 \mathrm{mmol} / \mathrm{l})$ nor on day $2(2.0 \pm 0.25$ vs $2.4 \pm 0.51)$, but was lower in SSTR2a- than in saline-treated rats on day 3 $(3.1 \pm 0.32$ vs $1.7 \pm 0.20 \mathrm{mmol} / 1, p<0.01)$. In the salinetreated animals, the mean glucose nadir was higher on day 1 than day $2(3.0 \pm 0.54 \mathrm{vs} 2.0 \pm 0.25 \mathrm{mmol} / \mathrm{l}, p=0.05)$, but occurred at a similar time after the start of exercise $(89 \pm 16$ vs 80 $\pm 16 \mathrm{~min}$ on days 1 and 2, respectively). In SSTR2a-treated animals, the glucose nadir tended to be higher on day 1 than on day $2(3.0 \pm 1.08$ vs $2.4 \pm 0.51 \mathrm{mmol} / \mathrm{l}, p=0.59)$. The time to glucose nadir in SSTR2a-treated rats did not differ between days ( $105 \pm 10$ vs $102 \pm 14$ min on days 1 and 2 , respectively) but tended to be longer than in saline-treated rats $(p=0.17)$.

Liver glycogen stores Figure 6 shows liver glycogen levels in the different groups with or without daily insulin treatment therapy. As shown, insulin therapy improved liver glycogen content in diabetic rats, increasing it from $29.4 \pm 19.8$ to 81.9

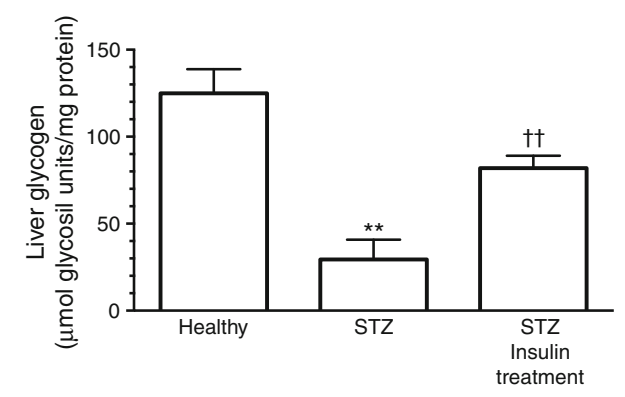

Fig. 6 Liver glycogen levels of non-diabetic rats (healthy) and of rats with STZ-induced diabetes, with or without daily insulin therapy. ${ }^{* *}$ Significantly different from healthy; ${ }^{\dagger \dagger}$ significantly different from healthy and STZ 
$\pm 14.2 \mathrm{mmol}$ glycosil units/mg protein $(p<0.01)$ but not to the level observed in the non-diabetic rats $(125.0 \pm 24.1 \mathrm{mmol}$ glycosil units/mg protein).

\section{Discussion}

We show that SSTR2a improves glucagon counterregulation during exercise performed in a hyperinsulinaemic state in diabetic rats. We also show that, despite enhanced glucagon responsiveness during exercise with recurrent antagonism, hypoglycaemia still occurs in early recovery from exercise in this model, likely because of sustained hyperinsulinaemia and an unsustained elevation in glucagon secretion, coupled with low glycogen stores. These findings are important in understanding the limits of the therapeutic potential of SSTR2a in type 1 diabetes and help shed light on the mechanisms for the high incidence of exercise-associated hypoglycaemia in patients living with the condition.

Aerobic exercise is generally thought to promote hypoglycaemia in type 1 diabetes because it enhances insulin-independent glucose disposal without promoting the usual reduction in insulin secretion to help augment hepatic glucose production [33]. Rather than drop during exercise, insulin levels tend to rise [14], likely because of enhanced blood flow and insulin absorption [34]. Other factors, such as impaired counterregulatory responses [33] or reduced hepatic glycogen stores [35], might also contribute to increased risk for exercise-induced hypoglycaemia. There may also be impairments in glucagon secretion during exercise [14], particularly in a setting of hypoglycaemia [7]. The blunted rise in the glucagon:insulin ratio in diabetes during aerobic exercise limits hepatic glucose production [36], and hypoglycaemia occurs in about half of the patient population $[7,37,38]$ unless preventive actions are taken [37-39].

In line with the clinical observations in humans of a blunted glucagon response to exercise [14], we demonstrate here that glucagon counterregulation is attenuated during exercise in diabetic rats (Figs 4 and 5). We also demonstrate, for the first time, that SSTR2a pretreatment augments the glucagon response during exercise-induced hypoglycaemia (Fig. 2). Importantly, we also show that glucagon responsiveness to this potential therapy is glucose sensitive, with the drug acting primarily to boost glucagon concentrations only during hypoglycaemia (Fig. 5). This finding supports our previous studies in which drug responsiveness occurred during clamped hypoglycaemia, but not during euglycaemia or hyperglycaemia [26]. Thus, this potential therapeutic should be considered as a way to improve glucagon counterregulation without sacrificing overall metabolic control by promoting sustained hyperglucagonaemia.

Even though SSTR2a treatment increases glucagon counterregulation and tends to delay the onset of hypoglycaemia during exercise, it does not dramatically lower overall hypoglycaemic risk in this model. These results extend our previous findings that an SSTR2a improves glucagon counterregulation in resting diabetic rats during acute $[25,26]$ and recurrent [27] hypoglycaemia, but also suggest that other factors are likely involved that drive exercise-associated hypoglycaemia. Relative hyperinsulinaemia during exercise, hepatic glucagon resistance and reduced hepatic glycogen stores are possible reasons why SSTR2a treatment was unsuccessful in ameliorating hypoglycaemia in this model. In support of the latter, although insulin therapy increased liver glycogen content in rats with STZ-induced diabetes, levels were not restored to those observed in non-diabetic animals (Fig. 6). Unfortunately, liver glycogen levels were not measured at the end of the exercise/hypoglycaemia protocol in this study, but rather after a 3 day recovery period when levels were likely somewhat restored by usual insulin therapy and ad libitum feeding (Fig. 6). Had liver glycogen been assessed when hypoglycaemia was induced, we may have observed even further diminished stores. A further reduction in liver glycogen content because of exercise and a prolonged hypoglycaemic state likely contributed to the failure of SSTR2a treatment to protect against hypoglycaemia. Although hepatic glucagon resistance is also a possibility, a recent study by Castle et al [40] showed that hepatic glucagon resistance does not occur in humans with type 1 diabetes, even after multiple exposures to exogenous glucagon. In our study, high prevailing insulin concentrations likely promoted increased glucose disposal during muscular exercise [41], thus limiting the effectiveness of glucagon at increasing hepatic glucose production, as is seen in patients with type 1 diabetes on bi-hormonal pump therapy who still develop hypoglycaemia with glucagon administration at rest [42, 43] and during exercise (R. Rabasa-Lhoret, Department of Nutrition \& Institut de Recherches Cliniques de Montréal, Faculty of Medicine, Université de Montréal, Montreal, QC, Canada, personal communication).

One alternative explanation for the failure to protect against hypoglycaemia in this study might be that glucagon concentrations, although increased with SSTR2a treatment, could not be sustained as the glucose was reaching its nadir (Fig. 4). These two phenomena are likely related: had the glucagon level been sustained at a higher level for a longer period with SSTR2a, the animals might not have reached hypoglycaemia (Fig. 5). This finding is consistent with the observation that SSTR2a treatment in pancreatic slices from diabetes-prone biobreeding (BBDP) rats increase glucagon secretion rates initially but then secretion rates drop even when hypoglycaemia is maintained [25]. Interestingly, although the pancreatic slices from BBDP rats treated with an SSTR2a drop their relative glucagon secretion rates over time in a hypoglycaemic setting, they have a robust secretion in response to subsequent arginine stimulation, thereby suggesting that diabetes itself alters the glucose-sensing and glucagon-secretion capacity 
of the alpha cell, rather than impairing glucagon content per se [25].

We chose a unique model for the induction of exerciseinduced hypoglycaemia that simulates what typically happens to type 1 diabetes patients when they exercise. However, some limitations of this model should be acknowledged. We used a modified in-house sliding scale equation for bolus insulin administration, which takes into account initial blood glucose levels and a target glucose concentration of $\sim 5.0 \mathrm{mmol} / \mathrm{l}$, in an attempt to modestly elevate relative insulin levels during exercise. However, insulin concentrations were not measured during this protocol and it is unclear if the SSTR2a promoted increased insulin secretion, which has been reported for cultured human islets [44]. Nonetheless, Yue et al [26] found no change in systemic insulin levels in rats with STZ-induced diabetes given SSTR2a, likely because SSTR5 is the main receptor isoform in beta cells in rats [25].

We gave mildly hyperglycaemic rats an insulin bolus that would normally result in relative hyperinsulinaemia during exercise, simulating exercise being performed after a mealtime insulin bolus. The combined effect of exercise with insulin administration resulted in a majority of rats developing hypoglycaemia by the end of exercise or in early recovery (Fig. 4). Importantly, insulin dose has been shown to have an important influence on the efficacy of an SSTR2a to augment hepatic glucose production [26]. When hypoglycaemia is induced with a minimum insulin dose ( $\sim 5 \mathrm{U} / \mathrm{kg} \mathrm{R}$ insulin), the glucose infusion rate necessary to maintain glucose in the target range is lower for SSTR2a-treated rats compared with saline-treated animals [26]. The lower glucose requirement during hypoglycaemia with an SSTR2a is associated with improved glucagon responsiveness, a finding that has recently been reported in the BBDP rat model [25]. Interestingly, when hypoglycaemia is induced with a higher insulin dose $(10 \mathrm{U} / \mathrm{kg}$ $\mathrm{R}$ insulin), no difference in glucose infusion rate is observed between drug-treated and control rats even though glucagon levels are elevated with the SSTR2a [26]. Taken together with our findings, it appears that SSTR2a treatment has little efficacy on glucose levels when circulating insulin levels are dramatically elevated, likely because of a relatively low glucagon:insulin ratio [36].

Liver glycogen content is implicated in recovery from exercise-induced hypoglycaemia. At least in theory, recovery from hypoglycaemia may be impaired despite glucagon counterregulation if the liver glycogen content is low because of a previous bout of hypoglycaemia, poor diabetes control or prolonged exercise. Poorly controlled diabetes in rats, even without exercise, dramatically diminishes liver glycogen stores [45], while intensive insulin treatment can help recover glycogen content to some degree [46], but can also increase hypoglycaemia risk. These findings are confirmed in our study as the non-diabetic rats had much higher baseline liver glycogen concentrations compared with the diabetic rats not treated with insulin (Fig. 6). Matsui et al [47] found that running on a treadmill for $30 \mathrm{~min}$ at $20 \mathrm{~m} / \mathrm{min}$ largely depletes liver glycogen levels in non-diabetic rats. We also found that daily insulin treatment improves, but does not fully restore, baseline liver glycogen content. Moreover, because the rats in our study were exercising while partially fasted on the day of experiment, liver glycogen content may well have been the limiting factor for their capacity to counterregulate, with SSTR2a treatment.

\section{Conclusion}

Our results show that SSTR2a treatment increases glucagon counterregulation in STZ diabetic rats during exercise, but animals still develop hypoglycaemia during early recovery. The failure to prevent hypoglycaemia after exercise despite SSTR2a treatment in this rodent model may be related to several factors including an unsustained glucagon counterregulation, relative hyperinsulinaemia and severely depleted liver glycogen stores. Thus, an SSTR2a may be considered a potential anti-hypoglycaemic agent for exercise, although its use may be limited by elevated prevailing insulin levels and compromised liver glycogen stores.

Funding This work was supported by MaRS Innovation, the JDRF and the Natural Sciences and Engineering Research Council of Canada (NSERC).

Duality of interest All authors made substantial contributions to the conception and design, acquisition of data or analysis and interpretation of data. They all helped with drafting the article or revising it critically for important intellectual content and gave final approval of the version to be published. Michael C. Riddell is the guarantor of this work.

Contribution statement The authors declare that there is no duality of interest associated with this manuscript.

\section{References}

1. Frier BM (2014) Hypoglycaemia in diabetes mellitus: epidemiology and clinical implications. Nat Rev Endocrinol 10:711-722

2. Miller KM, Foster NC, Beck RW et al (2015) Current state of type 1 diabetes treatment in the U.S.: updated data from the T1D Exchange clinic registry. Diabetes Care 38:971-978

3. Leiter LA, Yale JF, Chiasson JL, Harris S, Kleinstiver P, Sauriol L (2005) Assessment of the impact of fear of hypoglycemic episodes on glycemic and hypoglycemia management. Can J Diabetes 29: 186-192

4. Arbelaez AM, Xing D, Cryer PE et al (2014) Blunted glucagon but not epinephrine responses to hypoglycemia occurs in youth with less than 1 yr duration of type 1 diabetes mellitus. Pediatr Diabetes $15: 127-134$

5. Cryer PE (2015) Hypoglycemia-associated autonomic failure in diabetes: maladaptive, adaptive, or both? Diabetes 64:2322-2323 
6. MacDonald MJ (1987) Postexercise late-onset hypoglycemia in insulin-dependent diabetic patients. Diabetes Care 10:584-588

7. Tansey MJ, Tsalikian E, Beck RW et al (2006) The effects of aerobic exercise on glucose and counterregulatory hormone concentrations in children with type 1 diabetes. Diabetes Care 29:20-25

8. Tsalikian E, Mauras N, Beck RW et al (2005) Impact of exercise on overnight glycemic control in children with type 1 diabetes mellitus. J Pediatr 147:528-534

9. Davey RJ, Howe W, Paramalingam N et al (2013) The effect of midday moderate-intensity exercise on postexercise hypoglycemia risk in individuals with type 1 diabetes. J Clin Endocrinol Metab 98: 2908-2914

10. McMahon SK, Ferreira LD, Ratnam N et al (2007) Glucose requirements to maintain euglycemia after moderate-intensity afternoon exercise in adolescents with type 1 diabetes are increased in a biphasic manner. J Clin Endocrinol Metab 92:963-968

11. Riddell MC, Bar-Or O, Hollidge-Horvat M, Schwarcz HP (1985) Heigenhauser GJ (2000) Glucose ingestion and substrate utilization during exercise in boys with IDDM. J Appl Physiol 88:1239-1246

12. Tuominen JA, Karonen SL, Melamies L, Bolli G, Koivisto VA (1995) Exercise-induced hypoglycaemia in IDDM patients treated with a short-acting insulin analogue. Diabetologia 38:106-111

13. Zinman B, Murray FT, Vranic M et al (1977) Glucoregulation during moderate exercise in insulin treated diabetics. J Clin Endocrinol Metab 45:641-652

14. Mallad A, Hinshaw L, Schiavon M et al (2015) Exercise effects on postprandial glucose metabolism in type 1 diabetes: a triple-tracer approach. Am J Physiol Endocrinol Metab 308:E1106-1115

15. Basu R, Johnson ML, Kudva YC, Basu A (2014) Exercise, hypoglycemia, and type 1 diabetes. Diabetes Technol Ther 16:331-337

16. Ertl AC, Davis SN (2004) Evidence for a vicious cycle of exercise and hypoglycemia in type 1 diabetes mellitus. Diabetes Metab Res Rev 20:124-130

17. Chan O, Sherwin R (2013) Influence of VMH fuel sensing on hypoglycemic responses. Trends Endocrinol Metab 24:616-624

18. Gaisano HY, Macdonald PE, Vranic M (2012) Glucagon secretion and signaling in the development of diabetes. Front Physiol 3:349

19. Kumar U, Grant M (2010) Somatostatin and somatostatin receptors. Results Probl Cell Differ 50:137-184

20. Jones CW, Reynolds WA, Hoganson GE (1980) Streptozotocin diabetes in the monkey: plasma levels of glucose, insulin, glucagon, and somatostatin, with corresponding morphometric analysis of islet endocrine cells. Diabetes 29:536-546

21. Madsbad S, Hilsted J, Krarup T, Tronier B, Sestoft L (1983) Plasma somatostatin increases during hypoglycaemia in insulin-dependent patients with and without B cell function. Clin Endocrinol (Oxf) 19: 47-51

22. Orci L, Baetens D, Rufener C et al (1976) Hypertrophy and hyperplasia of somatostatin-containing D-cells in diabetes. Proc Natl Acad Sci U S A 73:1338-1342

23. Plesner A, Ten Holder JT, Verchere CB (2014) Islet remodeling in female mice with spontaneous autoimmune and streptozotocininduced diabetes. PLoS One 9:e102843

24. Alan L, Olejar T, Cahova M et al (2015) Delta cell hyperplasia in adult Goto-Kakizaki (GK/MolTac) diabetic rats. J Diabetes Res 2015:385395

25. Karimian N, Qin T, Liang T et al (2013) Somatostatin receptor type 2 antagonism improves glucagon counterregulation in biobreeding diabetic rats. Diabetes 62:2968-2977

26. Yue JT, Burdett E, Coy DH, Giacca A, Efendic S, Vranic M (2012) Somatostatin receptor type 2 antagonism improves glucagon and corticosterone counterregulatory responses to hypoglycemia in streptozotocin-induced diabetic rats. Diabetes 61:197-207

27. Yue JT, Riddell MC, Burdett E, Coy DH, Efendic S, Vranic M (2013) Amelioration of hypoglycemia via somatostatin receptor type 2 antagonism in recurrently hypoglycemic diabetic rats. Diabetes 62:2215-2222

28. Rodrigues B, Figueroa DM, Mostarda CT, Heeren MV, Irigoyen MC, De Angelis K (2007) Maximal exercise test is a useful method for physical capacity and oxygen consumption determination in streptozotocin-diabetic rats. Cardiovasc Diabetol 6:38

29. Carr RS, Neff JM (1984) Quantitative semi-automated enzymatic assay for tissue glycogen. Comp Biochem Physiol B 77:447-449

30. Cengiz E, Tamborlane WV (2009) A tale of two compartments: interstitial versus blood glucose monitoring. Diabetes Technol Ther 11(Suppl 1):S11-16

31. Iscoe KE, Davey RJ, Fournier PA (2012) Is the response of continuous glucose monitors to physiological changes in blood glucose levels affected by sensor life? Diabetes Technol Ther 14:135-142

32. Davey RJ, Low C, Jones TW, Fournier PA (2010) Contribution of an intrinsic lag of continuous glucose monitoring systems to differences in measured and actual glucose concentrations changing at variable rates in vitro. J Diabetes Sci Technol 4:1393-1399

33. Galassetti P, Riddell MC (2013) Exercise and type 1 diabetes (T1DM). Compr Physiol 3:1309-1336

34. Berger M, Halban PA, Assal JP, Offord RE, Vranic M, Renold AE (1979) Pharmacokinetics of subcutaneously injected tritiated insulin: effects of exercise. Diabetes 28(Suppl 1):53-57

35. Hwang JH, Perseghin G, Rothman DL et al (1995) Impaired net hepatic glycogen synthesis in insulin-dependent diabetic subjects during mixed meal ingestion. A 13C nuclear magnetic resonance spectroscopy study. J Clin Invest 95:783-787

36. Wasserman DH (2009) Four grams of glucose. Am J Physiol Endocrinol Metab 296:E11-21

37. Rabasa-Lhoret R, Bourque J, Ducros F, Chiasson JL (2001) Guidelines for premeal insulin dose reduction for postprandial exercise of different intensities and durations in type 1 diabetic subjects treated intensively with a basal-bolus insulin regimen (ultralente-lispro). Diabetes Care 24:625-630

38. Riddell MC, Bar-Or O, Ayub BV, Calvert RE, Heigenhauser GJ (1999) Glucose ingestion matched with total carbohydrate utilization attenuates hypoglycemia during exercise in adolescents with IDDM. Int J Sport Nutr 9:24-34

39. Tsalikian E, Kollman C, Tamborlane WB et al (2006) Prevention of hypoglycemia during exercise in children with type 1 diabetes by suspending basal insulin. Diabetes Care 29:2200-2204

40. Castle JR, El Youssef J, Bakhtiani PA et al (2015) Effect of repeated glucagon doses on hepatic glycogen in type 1 diabetes: implications for a bihormonal closed-loop system. Diabetes Care 38:2115-2119

41. Wasserman DH, Geer RJ, Rice DE et al (1991) Interaction of exercise and insulin action in humans. Am J Physiol 260:E37-45

42. El Youssef J, Castle JR, Bakhtiani PA et al (2014) Quantification of the glycemic response to microdoses of subcutaneous glucagon at varying insulin levels. Diabetes Care 37:3054-3060

43. Castle JR, Engle JM, El Youssef J, Massoud RG, Ward WK (2010) Factors influencing the effectiveness of glucagon for preventing hypoglycemia. J Diabetes Sci Technol 4:1305-1310

44. Brunicardi FC, Atiya A, Moldovan S et al (2003) Activation of somatostatin receptor subtype 2 inhibits insulin secretion in the isolated perfused human pancreas. Pancreas 27:e84-89

45. Khandelwal RL, Zinman SM, Knull HR (1979) The effect of streptozotocin-induced diabetes on glycogen metabolism in rat kidney and its relationship to the liver system. Arch Biochem Biophys 197:310-316

46. Okamoto MM, Anhe GF, Sabino-Silva R et al (2011) Intensive insulin treatment induces insulin resistance in diabetic rats by impairing glucose metabolism-related mechanisms in muscle and liver. J Endocrinol 211:55-64

47. Matsui T, Soya S, Okamoto M, Ichitani Y, Kawanaka K, Soya H (2011) Brain glycogen decreases during prolonged exercise. J Physiol 589:3383-3393 